\title{
The global value of water in agriculture
}

\author{
Paolo D’Odorico ${ }^{a}$, Davide Danilo Chiarellib ${ }^{\circ}$, Lorenzo Rosa ${ }^{a} \odot$, Alfredo Bini ${ }^{\mathrm{a}}{ }^{\circ}$, David Zilberman $^{\mathrm{c}, 1} \oplus$, \\ and Maria Cristina Rullib ${ }^{\mathbf{b}}$
}

\begin{abstract}
${ }^{\mathrm{a} D e p a r t m e n t ~ o f ~ E n v i r o n m e n t a l ~ S c i e n c e s ~ P o l i c y ~ a n d ~ M a n a g e m e n t, ~ U n i v e r s i t y ~ o f ~ C a l i f o r n i a, ~ B e r k e l e y, ~ C A ~ 94720 ; ~}{ }^{\mathrm{b}}$ Department of Civil and Environmental Engineering, Politecnico di Milano, 20131 Milano, Italy; and 'Department of Agricultural and Resource Economics, University of California, Berkeley, CA 94720
\end{abstract}

Contributed by David Zilberman, July 3, 2020 (sent for review March 30, 2020; reviewed by Petra Hellegers and Marc F. Müller)

\begin{abstract}
Major environmental functions and human needs critically depend on water. In regions of the world affected by water scarcity economic activities can be constrained by water availability, leading to competition both among sectors and between human uses and environmental needs. While the commodification of water remains a contentious political issue, the valuation of this natural resource is sometime viewed as a strategy to avoid water waste. Likewise, water markets have been invoked as a mechanism to allocate water to economically most efficient uses. The value of water, however, remains difficult to estimate because water markets and market prices exist only in few regions of the world. Despite numerous attempts at estimating the value of water in the absence of markets (i.e., the "shadow price"), a global spatially explicit assessment of the value of water in agriculture is still missing. Here we propose a data-parsimonious biophysical framework to determine the value generated by water in irrigated agriculture and highlight its global spatiotemporal patterns. We find that in much of the world the actual crop distribution does not maximize agricultural water value.
\end{abstract}

water value | water productivity | irrigation

W ater is a crucial resource for life on Earth because it is irreplaceable in its role of sustaining the functioning of environment and societies. Humankind uses water resources for drinking, municipal needs, and a number of economic activities. Among them, agriculture is the most water-demanding, claiming more than $85 \%$ of human water consumption (1).

Despite its important impacts on crop production, food security, and rural livelihoods, water often remains hidden in the economic valuation of agricultural assets. Unlike oil, it is seldom treated as a commodity and traded in the marketplace to generate revenues (2). Rather, it remains underpriced because users do not pay for its real value (3). Oftentimes farmers do not even pay for the provision costs associated with withdrawal and delivery $(4,5)$. Thus, while crops use huge amounts of water, the price of agricultural products seldom accounts for the cost of water consumption.

What is the value of water? How can it be determined? The valuation of water remains a difficult task because this natural resource is rarely traded and therefore its value cannot be determined from a market price. Of course, there are exceptions, such as bottled water, which accounts for less than $1 \%$ of human appropriation of water resources worldwide (1), the pricing of municipal water supply (less than $5 \%$ of total human consumption in all sectors), or the few water markets existing around the world $(6,7)$. In some of these cases, the market value (i.e., price) reflects the extrinsic value of water, expressed both by the users' willingness to pay and the willingness of water rights holders to accept compensation for relinquishing their water allocations (8). Water markets and water trading can be found in Australia, the United States, Mexico, Chile, China, Spain, and South Africa $(6,7,9,10)$. These are more exceptions than the rule because in most of the world there are no tradable water rights (11), the "conditio sine qua non" for the emergence of water markets (12). In other words, in many regions there are no water entitlements that can be sold or acquired through market transactions separately from the land. Rather, water is either tied to land's property rights or treated as a public good, "res nullius" (i.e., an open access resource), or a common pool resource (5).

Although not properly priced, water availability shapes the global patterns of agricultural production and trade $(13,14)$ and the associated flows of embodied or "virtual" water $(15,16)$, which is the water consumed in the production of goods such as crops (17). In fact, water-scarce regions need to import agricultural commodities to meet their food demand (17). Even when water is not directly commodified, the goods it contributes to produce are. The value of the associated virtual water, however, is seldom accounted for (18). Likewise, water is implicitly acquired with agricultural land in the form of rainwater and sometimes also irrigation water when blue water resources (i.e., water from surface water bodies or aquifers) are inherently appropriated with the land (19). This happens in regions where land ownership includes water rights or unregulated access to adjacent or underlying freshwater resources (20). Interestingly, while there are well-established methods to calculate the water resources that are virtually acquired with agricultural land (21), their economic value remains difficult to assess (18).

Because water pricing is often viewed as a mechanism to promote a more efficient use of water resources, an international agreement on water valuation is sometime considered to be crucial to the achievement of an efficient and sustainable global water use, a point that has been discussed at the World Water Forum in the last two decades $(3,22)$. The value of irrigation water in agricultural areas is an important piece of information for investors and financial groups engaged in the acquisition of land and water resources. Even in the absence of a water market,

\section{Significance}

Water's ability to generate value in irrigated agriculture remains poorly quantified at the global scale. The valuation of irrigation water is an important piece of information not only for agribusiness investors interested in the acquisition of land and water entitlements but also for farmers and rural communities that are negotiating with such investors. To make an informed decision about the acquisition or relinquishment of water rights or about investments in irrigation infrastructure there is a need for a better understanding of the value generated by irrigation water in agriculture using methods that rely on globally available data. This study provides a highresolution global assessment of irrigation water value as a function of crop type and geographic location.

Author contributions: P.D., A.B., and M.C.R. designed research; D.D.C., D.Z., and M.C.R. performed research; D.D.C. and L.R. analyzed data; and P.D. and D.Z. wrote the paper. Reviewers: P.H., Wageningen University and Research Center; and M.F.M., University of Notre Dame.

The authors declare no competing interest.

This open access article is distributed under Creative Commons Attribution-NonCommercialNoDerivatives License 4.0 (CC BY-NC-ND).

${ }^{1}$ To whom correspondence may be addressed. Email: zilber11@berkeley.edu.

This article contains supporting information online at https://www.pnas.org/lookup/suppl/ doi:10.1073/pnas.2005835117/-/DCSupplemental. 
land and agribusiness investors would benefit from knowing more about the potential economic value of the water resources they are virtually acquiring with the land. Indeed, the decision to invest along the banks of the Nile River or in areas suitable for rain-fed agriculture instead of targeting arid lands within the same regions would benefit from a combined hydrologic and economic analysis of the availability, productivity, and value of irrigation water. On the other hand, it could be argued that the valuation of water may favor its growing transnational control through the acquisition of water and land entitlements by selfinterested agribusiness corporations. This may happen if, as a result of the valuation and commodification of land and water resources, peasants decide to sell land and water rights to realize short-term profits without having the opportunity to plan for the long-term economic development of their communities $(23,24)$. At the same time, a major factor impeding planning for rural development is lack of awareness of the value of natural resources such as land and water. Indeed, local communities engaged in the negotiation of land and water concessions need to know the current and potential contribution of water resources to the creation of value in their farmland. Unbalanced power relations and asymmetry in the knowledge of the economic value of these assets are often major obstacles to the informed negotiation of land and water deals $(25,26)$. Likewise, investments in irrigation infrastructure require an assessment of the increase in production and associated profits resulting from the use of irrigation. Indeed, farmers' decision to adopt irrigation depends-among other factors - on the value generated by irrigation in the production process (27). There is a need for reliable and reproducible water valuation methods (18) that-in the absence of markets-can be used to determine the value of water embodied in agricultural land and its products.

The estimate of the value of water in the absence of market (or "shadow price") is often based on the marginal value produced by a unit volume of water $(28,29)$. The literature on this subject is often based on inductive statistical/econometric methods determining the value of water from empirical data, or on deductive models (e.g., postulating a rational behavior such as profit maximization) that are fitted to the data (8). Both approaches typically require a wealth of data (e.g., on irrigation water withdrawals and distribution, land transactions, crop production, and sale prices) that are seldom available, particularly in the developing world (30). These classes of methods fail to capitalize on process-based understanding of the underlying hydrological processes determining the role of water as a factor of production $(8,12,28)$. More recently, some studies have proposed a mixed model in which one of the factors of production (i.e., irrigation water consumption) is estimated with biophysical models while the shadow price of groundwater is determined either by fitting a function of production to empirical data (31) or by simulating the dynamics of crop growth accounting for their dependence on soil moisture and irrigation technology (32).

Here we use a completely mechanistic biophysical method for the valuation of water in agriculture that can be used even when tradable water rights do not exist. We carry out this valuation analysis for the 16 major crops at the global scale on a $10-\mathrm{km}$ grid and then map and critically analyze the results. Our approach allows for the worldwide valuation of water in agriculture and can be used to determine water's contribution to the value of both crop production and agricultural land.

\section{A Global Valuation of Water in Agriculture}

We propose a water valuation criterion that is based on the increased volume of agricultural outputs in irrigated land with respect to rain-fed conditions. This approach relies on a few simplifying assumptions. In fact, in principle water should be valued based on its opportunity costs, that is, on the net economic benefit an incremental unit of water would have generated in the best (i.e., most productive) alternative. When we consider the current use of water (i.e., the use in agriculture for the same crops that are actually planted), the water value is the net economic benefit, expressed as the net value of output produced, minus the cost of obtaining the water, environmental externality costs, and future cost. More specifically, the optimal value of water, $V_{w}$, should be determined according to

$$
V_{w}=\frac{P_{c} \Delta Y-\Delta C_{P}-\Delta P_{C}-\Delta E_{c}-\Delta F_{C}}{I W R},
$$

where IWR (irrigation water requirement) is the volume of irrigation water that will need to be applied per unit land area, $P_{c}$ is the crop output price, $\Delta Y$ is the incremental change in output associated with the use of irrigation (i.e., when the irrigation water requirements, IWR, are met), $\Delta C_{P}$ is the incremental production cost associated with the extra water (labor, fertilizer, and other inputs), $\Delta P_{C}$ is the incremental water provision cost (pumping, piping, investment in infrastructure and equipment, and their maintenance), $\Delta E_{C}$ is the incremental environmental externality cost reflecting the value water could have been generating in environmental services (i.e., the loss of environmental services associated with irrigation water consumption), and $\Delta F_{C}$ is future cost, the value that could have been generated by the water if it stayed in storage (e.g., in the case of groundwater depletion) and allowed for production in the future $(33,34)$.

Here we assume that the incremental costs associated with labor, land, seeds, fertilizer, and machineries, are negligible $\left(\Delta C_{P} \approx 0\right)$ because the cost of these inputs are about the same in irrigated and rain-fed conditions. We also concentrate on regions of the world in which irrigation can be adopted without engendering an unsustainable water use. When we expand the analysis to other regions we do not consider environmental externalities, assuming that the adoption of partial irrigation prevents the overuse of groundwater or environmental flows $(14,35)$. In other words, irrigation water withdrawals would neither cause the loss of environmental flows nor the depletion of groundwater stocks. If environmental flows are preserved, there would be no major additional environmental externality (with respect to rain-fed conditions) associated with loss of environmental flows and therefore we can assume that $\Delta E_{C} \approx 0$. The fact that we ensure that groundwater is not depleted allows us to assume that there are no future costs (i.e., $\Delta F_{C} \approx 0$ ). In other words, here we focus on the value generated by sustainable irrigation water. The cost of water provision associated with irrigation infrastructure and equipment and their operation, $\Delta P_{C}$, are in general harder to estimate and will also be assumed to be negligible, an assumption that will be critically analyzed in Discussion and tested against available data.

Thus, the value of irrigation water is here determined as the increased value of crop production,

$$
V_{w}=\frac{P_{c} \Delta Y}{I W R} .
$$

In other words, farmers' willingness to accept compensation for relinquishing water allocations and the willingness to pay of their counterparts should not exceed the added value of water estimated as water's contribution to the creation of value in the process of crop production. Details on the calculation of $\Delta Y$ and $I W R$ are presented in Methods. We do not consider situations where output prices are subsidized, leading to excessive water use (36) or output market are noncompetitive.

For every region of the world we estimate the increase in crop production afforded by irrigation water, calculate the irrigation water requirement, and estimate the value of water as the ratio between the value of the increase in crop production induced by irrigation and the associated irrigation water withdrawals. We will consider irrigation only in regions where a sufficient amount 
of water exists to allow for irrigation water requirements to be met without inducing a loss of environmental flows or groundwater stocks (14).

\section{Results}

The worldwide application of this framework to the crops currently planted in each location allows for an estimate of the maximum price farmers might accept to pay for irrigation water.

If we look at the four major staple crops $(\approx 60 \%$ of global food production), we find that the global mean water values are $\$ 0.05$, $\$ 0.16, \$ 0.16$, and $\$ 0.10 / \mathrm{m}^{3}$ for wheat, maize, rice, and soybean, respectively (SI Appendix, Table S1). The value of water for the production of maize, soybean, and rice is consistently higher than for wheat. These differences are the result of the combined effect of differences in crop price and in crop water use efficiency (amount of crop produced per unit water input). The values of water for maize and rice are substantially higher in East Asia than in other regions of the world (Fig. 1). Interestingly, for maize and rice the within-region variability in water value tends to be smaller than the variability among regions, while for wheat and soybean the water value variability tends to be relatively small both within region and across regions (Fig. 2). Results presented in this manuscript refer to water withdrawals because farmers are more likely to be allocated-and consequently account for and keep track of-volumes of water withdrawals than water consumption (i.e., the actual amount of water consumed by crops to sustain their production). Values of water based on consumption are presented in SI Appendix as well as in Fig. $1 B$. As expected, the water values determined with reference to water withdrawals are lower than those determined with reference to water consumption and the difference depends on the efficiency of the irrigation system (Figs. 1 and 3 and SI Appendix, Fig. S3).

Expanding the analysis to the 16 major crops $[\approx 70 \%$ of global food production (37)], we see that for all of them the global median and mean roughly range between $\$ 0.05$ and $\$ 0.25 / \mathrm{m}^{3}$. The only exception is represented by potatoes, which consistently exhibit a much greater water value than the other crops with a median value of $\$ 0.67 / \mathrm{m}^{3}$ (Fig. 3 and SI Appendix, Table S1). The higher values of water for potatoes is due to their higher yields per unit volume of water application and their higher price compared to the other crops; however, despite their widespread

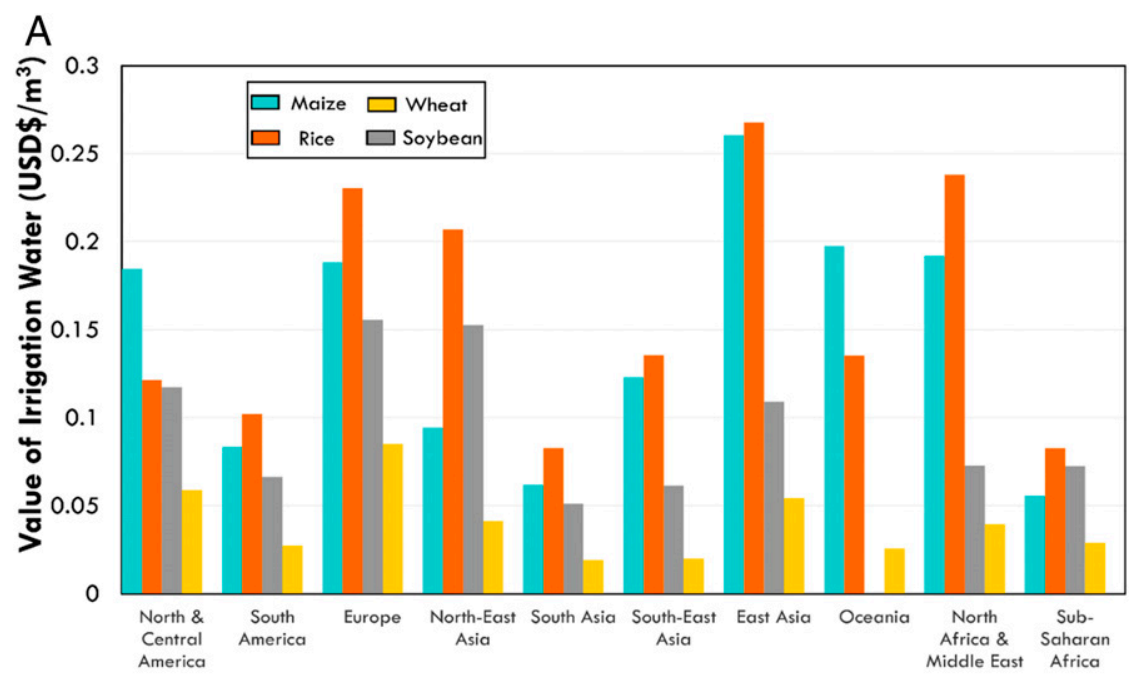

$\mathrm{B}$

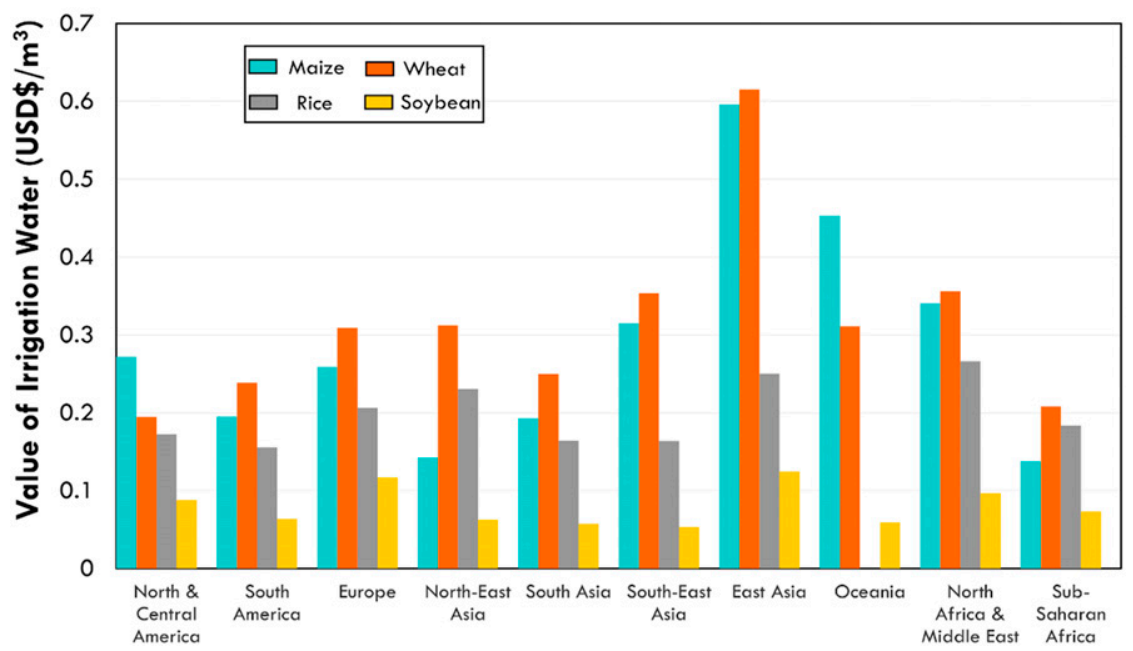

Fig. 1. Current irrigation water value (ca. year 2000, mean value) by region for four major staple crops accounting for $57 \%$ of global food calorie and $61 \%$ of global protein production for human consumption (36). (A) Values based on water withdrawals to meet irrigation water requirements with the existing technology (Methods). (B) Values based on water consumption (i.e., evapotranspiration) to meet irrigation water requirements. See SI Appendix, Fig. S1 for the definition of these geographic regions. 


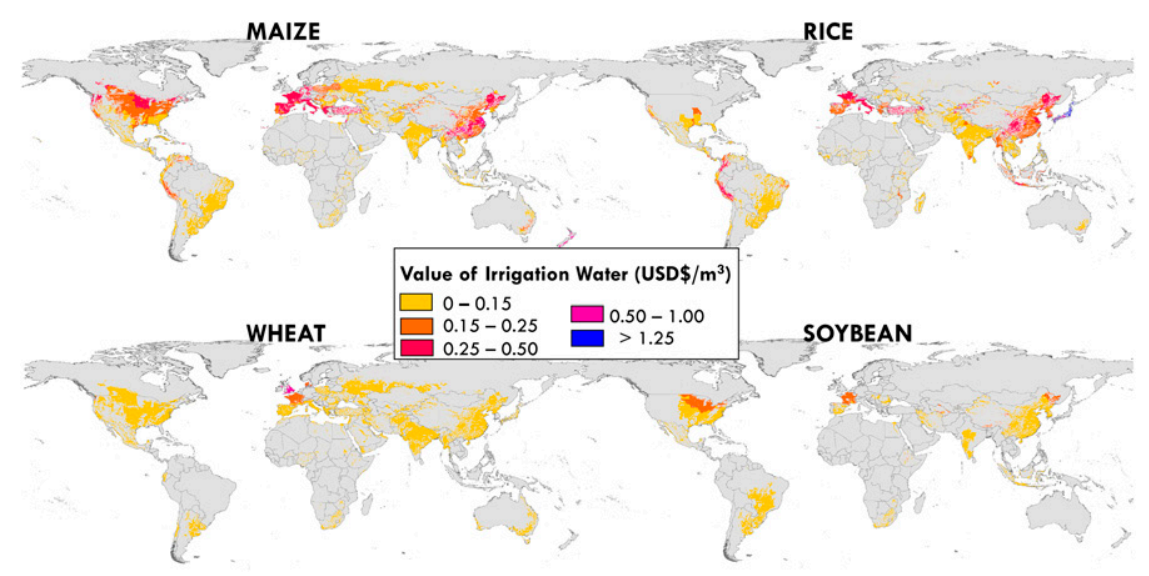

Fig. 2. Current (ca. year 2000) value of irrigation water used for irrigation of maize, wheat, soybean, and rice, based on water withdrawals.

use, potatoes contribute to only $2.1 \%$ of the global food calorie production and account for only $1.1 \%$ of the global irrigated areas (38). Variability in the mean water value across regions (using the current crop distribution) is overall smaller than that across crops and ranges from $\$ 0.09 / \mathrm{m}^{3}$ in South Asia to $\$ 0.42 / \mathrm{m}^{3}$ in Europe (Fig. 4A). With the current crop distribution, the global median and mean water values are $\$ 0.13$ and $\$ 0.23 / \mathrm{m}^{3}$, respectively (SI Appendix, Table S1). Interestingly, even though the within-region water value (averaged across the existing crops) can substantially vary (Fig. $5 A$ ), globally, the spread around these median and mean value is relatively small, with the $25 \%$ and $75 \%$ quartiles being $\$ 0.08$ and $\$ 0.42 / \mathrm{m}^{3}$ smaller and greater than the median, respectively (Fig. $4 B$ ).

We also provide an estimate of the maximum water values obtained considering - among all of the crops currently cultivated in every $10-\mathrm{km} \times 10-\mathrm{km}$ pixel - the crop associated with the maximum local water value. These results show that the current crop distribution does not maximize water value (i.e., the value of crops produced by irrigation water). In this analysis we have considered the global areas cultivated with the 16 major crops. Each crop has its own irrigation water requirements, yield, and price, which leads to different water values, depending on the crop. In Fig. $4 B$ we show the results for the crop that realizes the maximum value. Thus, while with the current crop distribution the median water value is $\$ 0.13 / \mathrm{m}^{3}$, if we consider only the crops with the maximum value, the median of the maximum values around the world becomes $\$ 0.54 / \mathrm{m}^{3}$ (Fig. $4 B$ and SI Appendix, Table S1). Interestingly, the variability in water value is greater for the maximum values than for the median values both across regions (Fig. 4) and within regions (Fig. 5B). The crops that maximize water value are potatoes in many regions of the world and sugarcane in South and Southeast Asia (SI Appendix, Fig. S2). Interestingly, these crops do not necessarily correspond to those that maximize the value of crop production per unit area. In fact, the irrigation water value is given by Eq. 2, while the crop value $\left(V_{\mathrm{C}}\right)$ can be calculated as

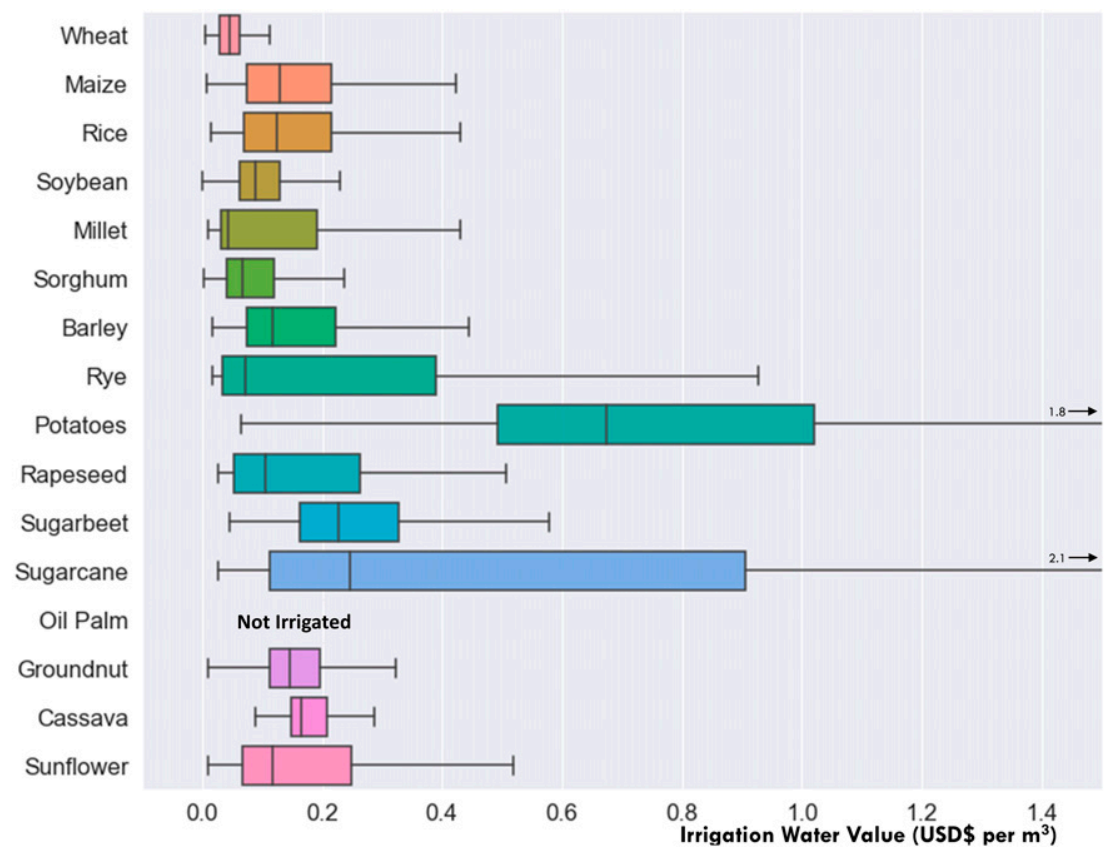

Fig. 3. Crop-specific irrigation water values. The box plots represent current (ca. year 2000) median, 25th, and 75th percentile and maximum and minimum values; outliers are not shown in the figure. These values are based on water withdrawals to meet irrigation water requirements with the existing technology (Methods). See SI Appendix, Fig. S3 for values based on water consumption. 

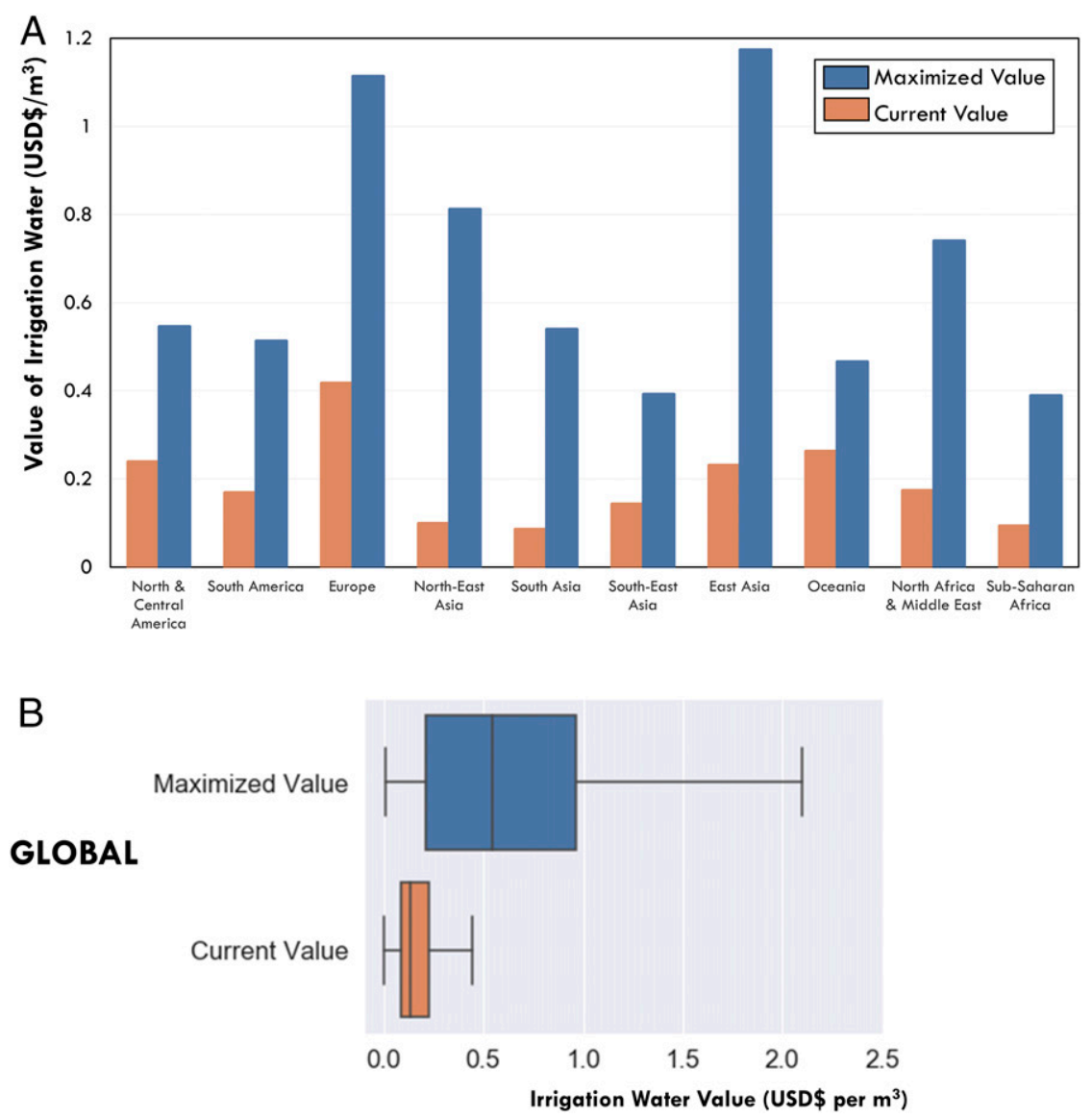

Fig. 4. Irrigation water value (mean value) considering current (ca. year 2000) crop distribution and the hypothetical distribution of crops that maximize the economic value of irrigation water (i.e., maximize water value; see Fig. 5). These water values are based on estimates of water withdrawals for irrigation. (A) Mean regional water values. $(B)$ Global statistics of irrigation water values. The box plots represent median, 25th, and 75th quartiles and maximum and minimum values; outliers are not shown in the figure. See SI Appendix, Fig. S1 for the definition of these geographic regions.

$$
V_{c}=P_{c} \times Y_{i}
$$

Thus, the value of crop A could exceed the value of crop B (i.e., $V_{c, \mathrm{~A}}>V_{c, \mathrm{~B}}$ ) even though the values of their irrigation water have an opposite relationship (i.e., $\left.V_{w, \mathrm{~A}}<V_{w, \mathrm{~B}}\right)$. This could happen, for instance, if the water use efficiency of $\mathrm{A}$ is greater than that of B. Crop production can be limited either by land (in regions with abundant water resources) or water (in relatively dry or seasonally dry regions). In the former case, farmers might use crops with low irrigation water use efficiency to maximize the value of their production per unit land area. In the latter, we would expect farmers to adopt deficit irrigation to optimize the use of water and select crops that maximize the value of crops per unit volume of irrigation water use (3).

Because a worldwide change in planted crops would turn into an academic exercise [in fact, it would dramatically alter crop prices (39) and consequently reshape the distribution of water values], in this study we just focus on the existing crop distribution. A farmer's decision to cultivate a given land parcel, the crop selection, and whether production will be irrigated depend on multiple factors. Here we do not attempt to model the dynamics underlying such decisions. Our focus is on the evaluation of the value generated by irrigation water in agricultural production for a given distribution of crops, which is based on the current distribution.

Further, we have investigated whether important differences in water value exist between areas where irrigation can be carried out sustainably or unsustainably. The water sustainability of irrigation depends on whether a sufficient amount of water resources is locally available to meet the crops' irrigation water requirement without depleting environmental flows or groundwater stocks, as in Rosa (14). Interestingly, the median water value for irrigation withdrawals is about the same in areas suitable for sustainable or unsustainable irrigation ( $\$ 0.14$ and $\$ 0.12 / \mathrm{m}^{3}$, respectively), while the mean values $\left(\$ 0.25\right.$ and $\$ 0.14 / \mathrm{m}^{3}$, respectively) and the variability ( $\mathrm{SD}=\$ 0.35$ and $\$ 0.12 / \mathrm{m}^{3}$, respectively) are much greater across the regions suitable for sustainable irrigation (Fig. $6 A$ ). The corresponding water values for the case of water consumption are presented in SI Appendix, Fig. S5.

Finally, the value of water is expected to change over time as a result of trends and fluctuations in crop prices, crop yields, and planted crops. For instance, in years of water scarcity farmers may see their profits increase as a result of the escalating prices despite the lower yields; alternatively, they might plant crops of higher value to offset the impacts of lower yields. If we look at the effect of interannual variability in irrigation water demand and availability, yields, and crop price at the farm gate, we observe important fluctuations in the value of water (Fig. $6 B$ ), including two major spikes corresponding to the escalation in food price in the food crises of 2008 and 2011. Consistent changes in water value across regions are largely due to difference in yields and crop water requirements.

\section{Discussion}

The economic valuation of water is a sensitive matter because it can be the premise to water pricing, commodification, and privatization, which are often contentious issues (22, 40-43). In fact, 


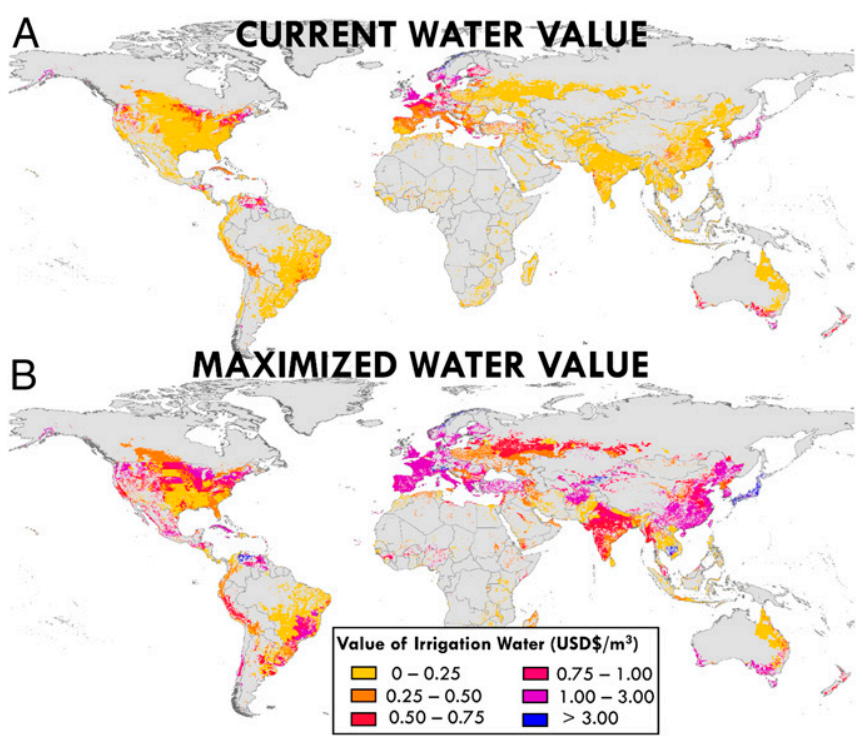

Fig. 5. Value of irrigation water withdrawals $(A)$ based on the existing (ca. year 2000) crop distribution and $(B)$ based on the crop that maximizes the value of irrigation water. SI Appendix, Fig. S2 for the correspondent crops that maximize the value of irrigation water. The corresponding values of irrigation water consumption are shown in SI Appendix, Fig. S4.

a large part of the public tends to think that water should be publicly owned because it is a natural resource that, like air, is essential for human life (5). Therefore, the valuation of water becomes particularly difficult when this resource is used not only for economic activities (e.g., agriculture or mining) but also for environmental needs or the fulfillment of human rights such as drinking or sanitation. Instead of dealing with these uses, here we explicitly focused on the value of water in agriculture. In most regions of the world farmers do not pay for the real value of irrigation water. In fact, in many cases they do not even pay for costs of water infrastructures (canals, dams, aqueducts, or wells) and their maintenance and operation (i.e., the provision costs, $\Delta P_{C}$ in Eq. 1), which are often subsidized by governmental agencies $(4,44)$. In addition to costs associated with the supply, treatment, storage, and distribution of freshwater resources, it is often argued that water itself (as a natural resource) should be sold to its users to avoid that it goes wasted or is used in economically inefficient ways $(45,46)$. From this perspective, economists often propose that farmers should pay for the real value of the water they use for irrigation. Because of the presence of subsidies, the real value of water in agriculture is different from the price paid by farmers (4). It is also different from the cost of delivery, which does not account for the value of water itself. However, what is the real value of water? In the absence of a market and associated market prices, the answer to this question is not straightforward (8). This paper developed an approach to determine the value generated by irrigation water as a factor of production in agriculture; using biophysical models we estimate the increase in crop production afforded by irrigation with respect to baseline rain-fed conditions. These estimates are then used to determine the maximum price that farmers would accept to pay for irrigation water.

The values presented in this study represent values in irrigation and food production. They may be excessive when they do not account for output subsidies or cost of investments in irrigation technology, the operating costs of irrigation due to additional labor and energy, and other inputs (e.g., to handle a more abundant harvest). In some cases, the annualized cost of irrigation infrastructure, and the maintenance, and operation costs, can be so high that they exceed the water values we have determined $(4,44)$. However, these costs are typically subsidized by the government and farmers only pay for part of them (5). Thus, our approach (i.e., the assumption that $\Delta P_{C} \approx 0$ in Eq. 1) would still determine the value of water to the farmers and provide a maximum reference value at which farmers might accept to sell or relinquish their water rights or water allocations to other businesses. The cost of irrigation infrastructures, their maintenance and operation are in general difficult to estimate on a global scale because of lack of data. Whether the assumption $\Delta P_{C} \approx 0$ (i.e., that the increase in output value resulting from irrigation by far exceeds the provision cost) is justifiable likely depends on a number of factors, including crop type and value, farm size, irrigation technology, and irrigation water source and its distance (both horizontal distance and depth) to the field. Global datasets for a worldwide validation of this assumption are not available. However, in Australia, the Bureau of Statistics reports the total cost of irrigation by region, including the costs of equipment, infrastructure, water license, and operation, in addition to data on irrigated areas and agricultural water withdrawals (47). A recent analysis of these data (48) has provided annual water provision costs per unit area of irrigated land. We can use these results to estimate the annual cost of water provision per unit volume of irrigation water and compare them to our estimates of the value of water. We find that provision costs typically range between US $\$ 0.01$ and $\$ 0.02 / \mathrm{m}^{3}$ (SI Appendix, Table S2). While in the case of some staple crops such as wheat or maize the value generated by irrigation is comparable (below US $\$ 0.05 / \mathrm{m}^{3}$; Fig. $6 B$ ), these water provision costs are overall negligible with respect to the average value of water in agriculture in Australia, which is here estimated at $\sim \$ 0.27 / \mathrm{m}^{3}$ (Fig. 4) in agreement with estimates $\left(\$ 0.17\right.$ to $\$ 0.40 / \mathrm{m}^{3}$; SI Appendix, Table S3) based on irrigation and production data from the Australian Bureau of Statistics (48). As noted below, these values fall within the interval of water prices reported by the MurrayDarling water market, suggesting that in the case of Australia the assumption of negligible provision costs can be overall justified.

The values of water found by this study fall within the range of those reported for water markets. In fact, we find median global values of $\$ 0.13 / \mathrm{m}^{3}$, while it has been reported that in 2012 Colorado farmers typically pay $\$ 0.02$ to $\$ 0.08 / \mathrm{m}^{3}$ for irrigation water (49). However, in the presence of competitors from the oil industry, farmers are outbid in water market transactions (50) at prices ranging from $\$ 0.81$ to $\$ 1.62 / \mathrm{m}^{3}$ in periods of water scarcity (49). This suggests that, when demand from another industry that is willing to pay a higher price for water comes into play, farmers sell their water rights if the price exceeds the value of water in agriculture. Our study provides an estimate of such a value. For instance, in 2012 in the case of maize, the value of water in the United States is here estimated at $\$ 0.25 / \mathrm{m}^{3}$, in general agreement with water trade data. For instance, in the Permian Basin in Texas, a computer application has been developed that connects owners of water rights to oil companies and allows them perform water transactions. While farmers would normally pay $\$ 0.05 / \mathrm{m}^{3}$, in periods of water scarcity, competition with shale oil and gas companies have brought the price to up to $\$ 2.50 / \mathrm{m}^{3}$ (51). Overall, in the presence of water markets and demand from oil companies, water prices may increase from $\$ 0.03-\$ 0.1 / \mathrm{m}^{3}$ to $\$ 2.3-\$ 3.1 / \mathrm{m}^{3}$ (52). Thus, in the presence of competition with other sectors capable of providing a more efficient use of water (in terms of revenue generated per cubic meter of water) the market price of water increases and farmers are outbid by oil companies at prices exceeding the agricultural water use efficiency determined by our study. In the Murray-Darling's water market (Australia) the median water price reported between 1998 and 2015 varied between $\$ 0.05 / \mathrm{m}^{3}$ (in periods of abundance) and $\$ 0.50 / / \mathrm{m}^{3}$ in periods of scarcity (53). These values are of the same order of magnitude as the 


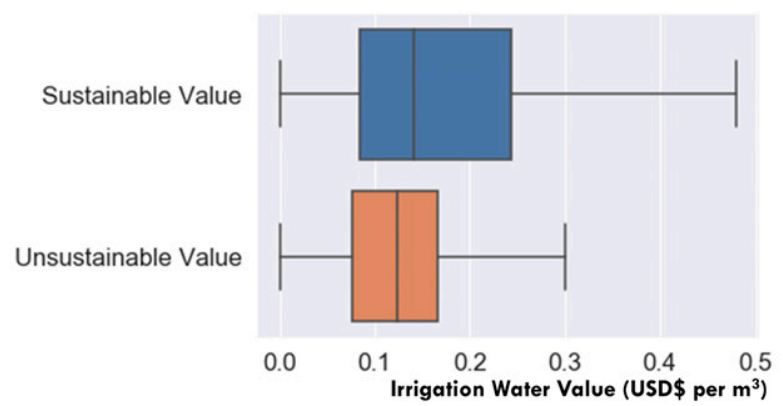

B

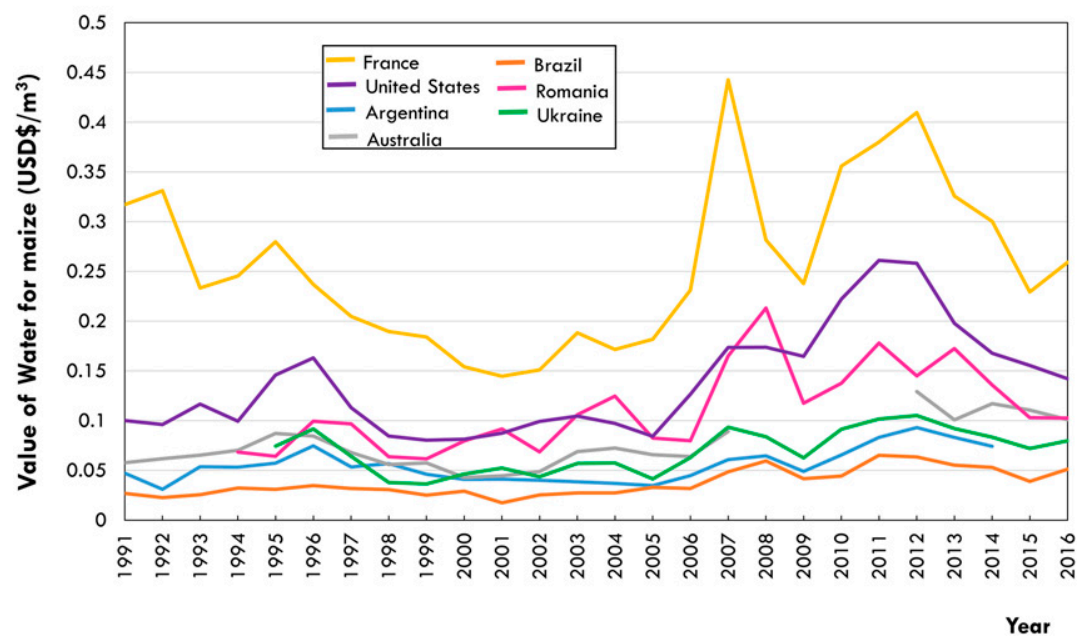

Fig. 6. (A) Value of irrigation water (based on withdrawals) in areas suitable for sustainable and unsustainable irrigation (based on existing crop distribution and irrigated areas). In the areas suitable for sustainable irrigation the water value has a more skewed tail toward higher irrigation water values. Sustainable and unsustainable irrigation areas were taken from Rosa (14). (B) Changes in the value of water between 1992 and 2016 as a result of interannual fluctuations in irrigation water demand, water availability, crop yields, and crop prices at the farm gate.

value of water in agriculture we have estimated for the MurrayDarling Basin (mean $\$ 0.21 / \mathrm{m}^{3}$, SD $\$ 0.29 / \mathrm{m}^{3}$ ).

Thus, in this study we calculate the value produced by water in its current use. The general pattern that is observed in the analysis of the economic water efficiency of water consumption is that with the current crop distribution the value of water in agriculture (expressed as the value generated by water in the production process) does not necessarily correspond to the "best use" of water because it does not exhibit the maximum water value (Fig. 5) and is at least one order of magnitude less than that in other sectors (mining, industrial, or municipal) (54). Therefore, in the presence of a water market water consumption is expected to shift from irrigation to the activity that maximizes revenue generation. However, the focus here is on the estimation of water values in agriculture not on how different uses (with different abilities to generate value) can compete with one another. In the case of water, such a competition is often limited by the lack of a market as a result of institutional or physical factors (e.g., water is heavy and is typically used locally). While water markets give a direct assessment of the value of water resulting from the complex interactions among different sectors, their existence is limited to those cases in which suitable tradeable property rights have been established. For the rest of the world the value of water can still be determined through its ability to produce value in different economic activities. Our results provide a first global estimate of the value of irrigation water worldwide.

\section{Methods}

The Value of Irrigation Water. If irrigation increases crop yield by $\Delta Y$ from the rain-fed yield, $Y_{r}$ (tons $\cdot$ ha $^{-1}$ ), to the irrigated yield, $Y_{i}=Y_{r}+\Delta Y$, assuming that labor and other input costs (seeds, fertilizer, and use of land and machineries) are about the same in irrigated and rain-fed conditions, the value of irrigation water in the production process is expected not to exceed the increased value of crop production.

We adopted the Doorenbos and Kassam (55) formula for crop yield evaluation as a function of evapotranspiration. This method is commonly used by FAO (56) and is based on the assumption that yields linearly scale with water consumption by plants. Indeed, plant growth (i.e., photosynthesis) and transpiration are coupled through stomatal regulation and they both scale linearly with stomatal conductance. Thus, a first-order model assuming a linear relationship between yields and evapotranspiration is based on reasonable ecohydrological bases $(57,58)$. Thus, the rain-fed yield, $Y_{r}$, is a fraction of the maximum irrigated crop yield $Y_{i}$ calculated as a function of the actual evapotranspiration $\left(E T_{a}\right)$ in rain-fed conditions and the potential evapotranspiration $(P E T)$ of crops, which is the maximum evapotranspiration that those crops would sustain in the absence of water limitations (i.e., in irrigated conditions),

$$
Y_{r}=Y_{i}\left(1-k_{y}\right)\left(1-\frac{E T_{a}}{P E T}\right),
$$

where $k_{y}$ is a crop yield response factor, a constant of proportionality in this linear relationship between yield and the consumptive water use (i.e., evapotranspiration) (56).

Blue water productivity is then the difference between maximum irrigated crop yield and rain-fed yield:

$$
\Delta Y=Y_{i}-Y_{r}
$$

The actual evapotranspiration $E T_{a}$ and the amount of water needed by irrigated agriculture to increase yields by $\Delta Y$ can be estimated with a crop water model accounting for a soil water balance coupled with an analysis of actual evapotranspiration $\left(E T_{a}\right)$ in rain-fed conditions and potential evapotranspiration $(P E T)$ in irrigated conditions. Specifically, we assessed the cumulative growing season $E T_{a}$ and $P E T$ for a set of 16 major crops (cassava, groundnut, millet, maize, oil palm, rice, rapeseed, potatoes, sunflower, soybean, sorghum, sugar beet, sugarcane, and wheat). These crops account for $73 \%$ of 
the planet's cultivated areas and contribute to about $70 \%$ of global food production (37). Around the year 2000 irrigation global maps and averaged irrigated crop yield (i.e., crop-specific values of $Y_{i}$ ) with a resolution of 5 arcmin (approximatively $10 \mathrm{~km}$ ) were taken from the MIRCA dataset (59). Actual evapotranspiration in rain-fed conditions, $E T_{a}$ (or "green water flows") and the potential evapotraspiration, $P E T$ (ET rate in the presence of adequate irrigation) were evaluated by solving a vertical soil water balance equation using the WATNEEDS model (60) at a resolution of $5 \mathrm{arcmin}$, in combination with a standard crop evapotranspiration model (61), expressing crop-specific $E T_{a}$ as the product of a reference evapotranspiration, $E T_{0}$, and a crop coefficient, $K_{\mathrm{c}}$ (accounting for the crop-specific planting dates and length and phases of the growing season), and a function $f(s) \leq 1$ of soil moisture, $s$ (from the soil water balance), accounting for the effect of water stress from soil moisture limitations (61). Likewise, crop-specific values of $P E T$ are calculated similarly to $E T_{a}$ but assuming that there is no water stress [i.e., $f(s)=1$ ]:

$$
\begin{aligned}
& E T_{a}=f(s) K_{c} E T_{0} \\
& P E T=K_{c} E T_{0} .
\end{aligned}
$$

Reference evapotranspiration, $E T_{0}$, was calculated with the PenmanMontieth method (61), using climate data from CPC (62) with a resolution of 30 arcmin for the period 2012 to 2016 and downscaled to 5 arcmin. Soil parameters were from the Harmonized World Soil Database (63) with a resolution of 5 arcmin. Crop parameters (i.e., $K_{c}$ values, growing periods and planting date were taken from ref. 38.

Irrigation water requirements, IWR, are then estimated as a function of the difference between crop water requirement, CWR, and rain-fed crop water consumption, $C W C_{r}$, calculated as the cumulative $P E T$ and the cumulative $E T_{a}$ in the course of the growing season, respectively. Thus, IWR is expressed as

$$
I W R=\frac{\left(C W R-C W C_{r}\right)}{e},\left(\mathrm{~m}^{3} \cdot \mathrm{ha}^{-1}\right)
$$

where $e$ is the irrigation efficiency, defined as the ratio between irrigation water withdrawals from surface water or groundwater bodies and irrigation water consumption (i.e., the amount of irrigation water transpired by crops) (64). Values of e depend on the type of irrigation system and we assumed $e=$ $0.50, e=0.70$, and $e=0.95$ in the case of surface, sprinkler, and drip irrigation respectively (65). The results presented in this study use crop-specific irrigation technology reported by Sauer et al. (65) for every region of the world.

Thus, the increase in production, $\Delta Y$ (tons $\cdot \mathrm{ha}^{-1}$ ), afforded by irrigation requires an amount of irrigation water equal to $I W R\left(\mathrm{~m}^{3} \cdot \mathrm{ha}^{-1}\right)$. The irrigation water use efficiency of that crop is $I W U E=\Delta Y / I W R\left(\right.$ tons $\left./ \mathrm{m}^{3}\right)$. If $P_{c}$ is the crop's price (\$/ton), the maximum value of water for that crop is

1. M. Falkenmark, J. Rockström, Balancing Water for Humans and Nature: The New Approach in Ecohydrology, (Earthscan, Sterling, VA, 2004).

2. J. Selby, Oil and water: The contrasting anatomies of resource conflicts. Gov. Opposition 40, 200-224 (2005).

3. A. Y. Hoekstra, The Water Footprint of Modern Consumer Society, (Routledge, New York, 2013).

4. R. W. Wahl, Markets for Federal Water: Subsidies, Property Rights, and the Bureau of Reclamation, (RFF Press, Washington, DC, 1989).

5. S. C. Anisfeld, Water Resources, (Island Press, Washington, DC, 2010)

6. P. Debaere et al., Water markets as a response to scarcity. Water Policy 16, 625-649 (2014).

7. T. Endo, K. Kakinuma, S. Yoshikawa, S. Kanae, Are water markets globally applicable? Environ. Res. Lett. 13, 034032 (2018).

8. R. A. Young, J. B. Loomis, Determining the Economic Value of Water: Concepts and Methods, (RFF Press, Washington, DC, 2014).

9. J. Carey, D. L. Sunding, D. Zilberman, Transaction costs and trading behavior in an immature water market. Environ. Dev. Econ. 2002, 733-750 (2002).

10. X. H. Deng, Z. M. Xua, X. Y. Song, J. Zhou, Transaction costs associated with agricultural water trading in the Heihe River Basin, Northwest China. J. Agri. Water Manag. 186, 29-39 (2017).

11. B. Richter, Water Share: Using Water Markets and Impact Investment to Drive Sustainability, (The Nature Conservancy, Washington, DC, 2016).

12. R. C. Johansson, Y. Tsur, T. L. Roe, R. Doukkali, A. Dinar, Pricing irrigation water: A review of of theory and practice. Water Policy 4, 173-199 (2002).

13. L. Rosa, D. Chiarelli, C. Tu, M. C. Rulli, P. D'Odorico, Global unsustainable virtual water flows in agricultural trade. Environ. Res. Lett. 14, 114001 (2019).

14. L. Rosa, Closing the yield gap while ensuring water sustainability. Environm. Res. Lett. 13, 104002 (2018)

15. P. Debaere, The global economics of water: Is water a source of comparative advantage? Am. Econ. J. Appl. Econ. 6, 32-48 (2014).

16. P. D'Odorico et al., Global virtual water trade and the hydrological cycle: Patterns, drivers, and socio-environmental impacts. Environ. Res. Lett. 14, 053001 (2019).

$$
V_{W}=P_{c} \times I W U E=P_{c} \times \frac{\Delta Y}{I W R} .
$$

In this analysis $P_{c}$ is the crop price at the farm gate, based on data from the FAO (66). The use of farm gate prices is motivated by the need to determine the value of water from the farmers' standpoint. We stress that this is not the actual water price that farmers pay or would pay for water, but the added value of water to the production process. In other words, if water is explicitly treated as a factor of production in agriculture, this method estimates water's contribution to the creation of economic value in the process of crop production. We also notice that this method estimates the value of irrigation water withdrawals (Eq. 6), assuming that any expected form of water regulation, allocation, and pricing is based on the volumes of water withdrawn from surface water bodies or aquifers. The valuation of water consumption for irrigation, however, can be obtained with the same methods by assuming that $e=1$. The results of these analyses are shown in Fig. $1 B$ and in SI Appendix, Figs. S3-S5.

Assessing the Value of Sustainable and Unsustainable Irrigation Water. In some regions of the world, even though irrigation can substantially increase crop production, no water is locally available for irrigation or only a fraction of the land could be sustainably irrigated. These conditions of irrigation water scarcity (or "blue water scarcity") were mapped by Rosa (14). Here, we repeat the analyses described in the previous section overlaying maps of sustainable and unsustainable irrigation water consumption data (14) to assess the value of irrigation water in currently sustainably and unsustainably irrigated croplands, separately.

Data Availability. Data used to perform this work can be found in SI Appendix and in the reference list. Model outputs are available in the Zenodo repository at https://doi.org/10.5281/zenodo.3974865.

ACKNOWLEDGMENTS. P.D. was supported by the USDA Hatch Multistate project W4190 capacity fund. L.R. was supported by the AGU Horton Hydrology Research Grant. D.Z. was supported by National Science Foundation, Chemical, Bioengineering, Environmental, and Transport Systems grant 2030362 and the Giannini Foundation of Agriculture Economics. M.C.R. and D.D.C. were supported by the ENI Enrico Mattei Foundation and by the Cariplo Foundation (SUSFEED project 0887 CUP D44I19001030007). CPC global unified precipitation data were provided by the National Oceanic and Atmospheric Administration/Oceanic and Atmospheric Research/Earth System Research Laboratory Physical Sciences Laboratory, Boulder, CO, from their website at https:// psl.noaa.gov/data/gridded/data.cpc.globalprecip.html.

17. J. A. Allan, Virtual water: A strategic resource global solutions to regional deficits. Ground Water 36, 545-546 (1998).

18. D. E. Garrick et al., Valuing water for sustainable development. Science 358 1003-1005 (2017).

19. M. C. Rulli, P. D'Odorico, The water footprint of land grabbing. Geophys. Res. Lett. 40, 1-6 (2013).

20. D. Bossio et al., Water implications of foreign direct investment in Ethiopia's agricultural sector. Water Altern. 5, 223 (2012).

21. M. C. Rulli, A. Saviori, P. D'Odorico, Global land and water grabbing. Proc. Natl. Acad. Sci. U.S.A. 110, 892-897 (2013).

22. J. J. Schmidt, "Valuing water rights, resilience, and the UN high-level panel on water" in Water Politics Governance, Justice and the Right to Water, F. Sultana, A. Loftus, Eds. (Routledge, London, 2019), pp. 15-27.

23. J. Skinner, L. Cotula, Are land deals driving 'water grabs'? IIED (2011). https://pubs. iied.org/17102IIED/. Accessed 6 August 2020.

24. J. Von Braun, R. S. Meinzen-Dick, "Land Grabbing" by Foreign Investors in Developing Countries: Risks and Opportunities, (International Food Policy Research Institute Washington, DC, 2009).

25. R. Knight, "Balancing the numbers: Using grassroots land valuation to empower communities in land investment negotiations" in 2015 Land and Poverty Conference, (The World Bank, Washington, DC, 2015), p. 23.

26. J. Dell'Angelo, P. D'Odorico, M. C. Rulli, The global water grab syndrome. Ecol. Econ. 143, 276-285 (2018)

27. K. Schoengold, D. Zilberman, "The economics of water, irrigation, and development" in Handbook of Agricultural Economics, (Elsevier, 2007), Vol. 3, pp. 2933-2977.

28. D. Pearce, Economic Values and the Natural World, (MIT Press, Cambridge, MA, 1993)

29. A. Dinar, V. Pochat, J. Albiac-Murillo, Eds., Water Pricing Experiences and Innovations, (Springer International Publishing, New York, 2015).

30. S. Buck, M. Auffhammer, D. Sunding, Land markets and the value of water: Hedonic analysis using repeat sales of farmland. Am. J. Agric. Econ. 96, 953-969 (2014).

31. M. F. Bierkens, S. Reinhard, J. A. de Bruijn, W. Veninga, Y. Wada, The shadow price of irrigation water in major groundwater-depleting countries. Water Resour. Res. 55, 4266-4287 (2019). 
32. U. Shani, Y. Tsur, A. Zemel, D. Zilberman, Irrigation production functions with watercapital substitution. Agric. Econ. 40, 55-66 (2009).

33. D. Pearce, A. Markandya, Marginal opportunity cost as a planning concept in natura resource management. Ann. Regional Sci. 21, 18-32 (1987).

34. E. P. Fenichel et al., Measuring the value of groundwater and other forms of natural capital. Proc. Natl. Acad. Sci. U.S.A. 113, 2382-2387 (2016).

35. L. Rosa et al., Global agricultural economic water scarcity. Sci. Adv. 6, eaaz6031 (2020)

36. E. Lichtenberg, D. Zilberman, The welfare economics of price supports in US agriculture. Am. Econ. Rev. 76, 1135-1141 (1986).

37. P. D'Odorico, J. A. Carr, F. Laio, L. Ridolfi, S. Vandoni, Feeding humanity through global food trade. Earths Futur. 2, 458-469 (2014).

38. S. Siebert, P. Döll, Quantifying blue and green virtual water contents in global crop production as well as potential production losses without irrigation. J. Hydrol. (Amst.) 384, 198-217 (2010)

39. K. F. Davis, M. C. Rulli, A. Seveso, P. D'Odorico, Increased food production and reduced water use through optimized crop distribution. Nat. Geosci. 10, 919-924 (2017).

40. K. Bakker, Privatizing Water: Governance Failure and the World's Urban Water Crisis, (Cornell University Press, 2010)

41. C. J. Bauer, Against the Current: Privatization, Water Markets, and the State in Chile (Springer Science and Business Media, New York, 2012), Vol. 14

42. E. Swyngedouw, Dispossessing $\mathrm{H} 2 \mathrm{O}$ : The contested terrain of water privatization Capitalism Nat. Socialism 16, 81-98 (2005).

43. L. Mehta, G. J. Veldwisch, J. Franco, Introduction to the special issue: Water grabbing? Focus on the (re)appropriation of finite water resources. Water Altern. 5, 193 (2012).

44. S. P. Holland, M. R. Moore, Cadillac desert revisited: Property rights, public policy, and water-resource depletion. J. Environ. Econ. Manage. 46, 131-155 (2003).

45. R. C. Griffin, Water Resource Economics: The Analysis of Scarcity, Policies, and Projects, (MIT Press, Cambridge, MA, 2006).

46. R. Brooks, E. Harris, Efficiency gains from water markets: Empirical analysis of Watermove in Australia. Agric. Water Manage. 95, 391-399 (2008).

47. Australian Bureau of Statistics, Agriculture. https://www.abs.gov.au/Agriculture. Accessed 6 August 2020

48. E. Borsato, L. Rosa, F. Marinello, P. Tarolli, P. D'Odorico, Weak and strong sustain ability of irrigation: A framework for irrigation practices under limited water availability. Front. Sustain. Food Syst. 4, 17 (2020).

49. J. Healy, For farms in the West, oil wells are thirsty rivals. NY Times, 5 September 2012 https://www.nytimes.com/2012/09/06/us/struggle-for-water-in-colorado-with-risein-fracking.html. Accessed 6 August 2020.
50. L. Rosa, M. C. Rulli, K. F. Davis, P. D'Odorico, The water-energy nexus of hydraulic fracturing: A global hydrologic analysis for shale oil and gas extraction. Earths Futur. 6, 745-756 (2018).

51. J. Yang, The new "Water Barons": Wall Street mega-banks are buying up the World's water. Global Research (2012). https://www.globalresearch.ca/the-new-water-baronswall-street-mega-banks-are-buying-up-the-worlds-water/5383274. Accessed January 2020.

52. M. Cook, M. Webber, Food, fracking, and freshwater: The potential for markets and cross-sectoral investments to enable water conservation. Water 8, 45 (2016).

53. Aither, "Supply-side drivers of water allocation prices-Identifying and modelling supply-side drivers of water allocation prices in the southern Murray-Darling Basin." https://www.agriculture.gov.au/water/markets/supply-side-drivers (2016).

54. FAO, "Progress on water use efficiency-Global baseline for SDG 6 Indicator 6.4.1" (FAO/UN-Water, FAO, Rome, 2018).

55. J. Doorenbos, A. H. Kassam, Yield response to water. FAO Irrig. Drain. Pap. 33, 257 (1979).

56. P. Steduto, T. C. Hsiao, D. Raes, E. Fereres, AquaCrop-The FAO crop model to simulate yield response to water: I. Concepts and underlying principles. Agron. J. 101, 426-437 (2009)

57. G. S. Campbell, J. M. Norman, An Introduction to Environmental Biophysics, (Springer, New York, ed. 2, 1997)

58. D. Molden et al., Improving agricultural water productivity: Between optimism and caution. Agric. Water Manage. 97, 528-535 (2010).

59. F. T. Portmann, S. Siebert, P. Döll, MIRCA2000-Global monthly irrigated and rainfed crop areas around the year 2000: A new high-resolution data set for agricultural and hydrological modeling. Global Biogeochem. Cycles 24 (2010).

60. D. D. Chiarelli et al., Global gridded dataset of crop-specific green and blue water requirements, the WATNEEDS model. Sci. Data, 10.1038/s41597-020-00612-0 (2020) In press.

61. R. Allen, L. Pereira, D. Raes, M. Smith, "Guidelines for computing crop water requirements" (FAO Drainage and Irrigation Paper 24, FAO, Rome, 1998).

62. CPC, Global unified precipitation data. https://psl.noaa.gov/data/gridded/data.cpc. globalprecip.html (NOAA/OAR/ESRL PSD, Boulder, CO). Accessed 6 August 2020.

63. FAO, JRC: Harmonized World Soil Database (Version 1.2, FAO, Rome, Italy and IIASA, Laxenburg, Austria, 2012).

64. M. F. Caswell, D. Zilberman, The effects of well depth and land quality on the choice of irrigation technology. Am. J. Agric. Econ. 68, 798-811 (1986).

65. T. Sauer et al., Agriculture and resource availability in a changing world: The role of irrigation. Water Resour. Res. 46, W06503 (2010).

66. FAOSTAT, Statistical databases (FAO, Rome, 2019). Accessed 17 October 2019. 